\title{
TITLE: SALVAGING COCHLEAR IMPLANT AFTER SUSPECTED BIOFILM INFECTION- Our experience
}

\author{
NEERAJ SURI ${ }^{1}$, satya sandilya ${ }^{1}$, and Manav Suri ${ }^{2}$ \\ ${ }^{1}$ GMERS Medical College and Hospital \\ ${ }^{2}$ Civil Hospital Ahmedabad
}

July 25, 2020

\begin{abstract}
Five patients presented with infection and an exposed cochlear implant and we decided to salvage them by attempting use of new antimicrobial treatment for biofilms using betaine surfactant and polyhexanide along with wound debridement and double layered vascularized flap. This is the first study demonstrating the use of betaine surfactant and polyhexanide in the management of biofilm in cochlear implants and we could salvage four infected cochlear implants by the aforementioned method. Early intervention can significantly improve salvage outcomes in cochlear implants infected with biofilms.
\end{abstract}

Type of article: Correspondence: Our Experience

\section{TITLE: SALVAGING COCHLEAR IMPLANT AFTER SUSPECTED BIOFILM INFECTION- Our experience}

\section{Key points:}

- We describe a novel procedure using betaine surfactant and polyhexanide for biofilm in cochlear implants.

- Early intervention along with wound debridement, double layer vascularized flap and rifampicin helps in salvaging the implant.

- Leaving the array in cochlea avoids fibrosis and can be considered for cochlear implantation at a later stage.

- This novel procedure significantly limits morbidity and repeated surgeries.

Key words: Cochlear Implants, Biofilm, Polyhexanide.

\section{INTRODUCTION:}

The cochlear implant is considered to be a very effective and safe surgical procedure that provides a world of sound to patients who are rendered deaf or hard of hearing. Unfortunately, infections happen years after implantation with dreaded cases of device exposure and poor prognosis. One of the reasons for limited effectiveness of antibiotics is the presence of biofilm on the device. ${ }^{1}$ Thus, the knowledge of complications is essential to facilitate the best possible early management and treatment especially flap related complications such as hematoma, necrosis and infections. The percentage of infections in cochlear implant patients range from $1.7 \%$ to $4.1 \%,{ }^{2,3}$ the severity of infections is difficult to predict at that stage and can lead to device removal despite rigorous medical and surgical efforts to eradicate the infection.

Biofilms are heterogeneous communities that are continuously changing. The microorganisms synthesize and secrete a protective matrix that attaches the biofilm firmly to a living surface. Any attempt at conservative 
management would fail unless the eradication of biofilm from the implant surface takes place. Recent literature supports the role of tea tree oil and Hydrogen peroxide in eradicating biofilm. ${ }^{4}$

Underlying bacterial infections and chronic inflammation leads to the formation of biofilm. Because biofilms are found on the surface of many medical devices, ${ }^{5,6}$ and also in infections in other parts of body, we aimed at using new agents having antimicrobial activity along with surgical debridement, double layer vascularised soft tissue cover and using oral rifampicin post operatively.

\section{MATERIAL AND METHODS:}

This is a prospective study done at [removed for blind peer review] from 2015-2018. Five patients who presented in the ENT OPD with cochlear implant infection were included in the study. The audiological follow up indicated a functional implant with no clinical features suggestive of meningitis or systemic infection. Despite a rigorous course of antibiotics there was recurrent swelling and discharge at the operated site in these patients.

However, in two patients implant was exposed along with discharge.

\section{(Figure 1)}

We decided to salvage the implant, and our surgical plan included:

1. Local wide excision of swelling. (Figure 2)

2. Exposure of cochlear implant.

3. Dipping the implant body in $6 \%$ hydrogen peroxide for 1 hour while the magnet was removed from the pocket and treated separately, both in hydrogen peroxide and Polyhexanide solution.

4. Dipping the implant body in Polyhexanide and Betaine surfactant for half an hour.

5. Filling the mastoid cavity with polyhexanide and betaine solution taking care that the electrodes doesn't come out of cochlea while lifting the implant body.

6. Debridement of biofilm (visually seen as gelatinous mass in the wound), drilling new bed and tunnel.

7. Preparing double layered vascularized soft tissue flap.

8. Changing the packing at the cochleostomy site after placing the implant body in its position and replacing the same magnet.

9. Before closure, an anti-biofilm solution was filled in the mastoid cavity and polyhexanide gel was applied on the bed and flap cover.

10. Neural response telemetry (NRT) was done to normal functioning of the implant.

Post operatively- Injection Augmentin (50-60mg/kg/day), Injection Piperacillin + Tazobactam (200$300 \mathrm{mg} / \mathrm{kg} /$ day) were given for 10 days followed by oral antibiotics for a week and oral Rifampicin (10 $\mathrm{mg} / \mathrm{kg} /$ day) for 6 months. Patients were discharged on the 10th day of surgery. A histopathological examination of the biofilm showed chronic inflammation. One year after the surgery, there were no signs of infection and patients are in follow up (Figure 3). One patient presented a recurrent infection for three weeks and we decided to take out the implant, leaving the array in the cochlea in order to avoid fibrosis and cochlear ossification. In the first month of the follow up, one patient presented some swelling and discharge from the flap which was infected with Pseudomonas aeruginosa. We explanted the patient without undergoing any further salvage surgeries. After a follow up period of one year, none of the patients on examination presented any sign of implant infection and are still in follow up. (Table 1)

\section{DISCUSSION:}

It is uncommon for cochlear implants to be complicated by microbial infection. However, when infections occur, sometimes it can be difficult to treat with antibiotic therapy, and may require explanting the cochlear implant. ${ }^{3}$ there are studies demonstrating that infection of cochlear implants is due to biofilm formation.

The biofilms act as reservoirs, capable of releasing individual bacteria into the surrounding tissue, thereby causing recurrent episodes of infection which may persist, despite intensive antimicrobial therapy, until the device is removed. In addition, as the role of biofilm formation in human infections becomes more clearly 
defined, cochlear implant surgeons should be prepared to deal with the unique demands of biofilm-related infection as they arise. ${ }^{4}$

Till date there are no straightforward guidelines to deal with biofilm infection and no standardized treatment to salvage the implant.

We made our protocol regarding the management of biofilm (Figure 4 ). No form of debridement or cleansing is likely to remove all biofilm and it still has the potential to regrow and form a layer again within days. The novel technique of using surfactant properties of polyhexanide and surfactant component (Betaine) reduces surface tension and aids in the removal of debris and bacteria. Applying the gel on the bed and flap cover prevents the regrowth of biofilm. We now routinely give a wash of the antimicrobial solution before taking sutures. $^{7}$

Common microorganisms isolated and reported are Staphylococcus aureus, Staphylococcus epidermidis and Pseudomonas aeruginosa. ${ }^{5,6,7}$

We suspected biofilms in our patients due to the recurrence of infections, despite antibiotic therapy. Macroscopically, rubbery, poorly vascularized granulomatous tissue is the hallmark of such infections. ${ }^{8}$ Their growth rate and sharing of antibiotic resistance genes within the bacteria makes them refractory to most aggressive antibiotic regimens. They can be demonstrated on the device surface using scanning electron microscopy. ${ }^{9}$ To the best of our knowledge no other study has reported an in vitro/in vivo use of polyhexanide for cochlear implant infections. An antibacterial effective amount of polyhexanide is adsorbed on the surface of titanium alloy and it is eligible method for preventing implant associated pseudomonas aeruginosa, staphylococcus aureus and staphylococcus epidermidis. ${ }^{10}$

In our Indian setup there are financial difficulties in obtaining new implant devices and the patient gets into auditory deprivation which is a matter of concern Our first aim was to salvage the functioning implant so the financial burden would be lesser than getting a new device.

In a study, 1 percent tea tree oil failed to eradicate biofilm growth at one hour; 5 percent tea tree oil proved sufficient to completely eradicate the biofilm formed by the cochlear implant Methicillin-sensitive S aureus isolate. ${ }^{4}$ However, there are other organisms being isolated from biofilms and polyhexanide can work against them. ${ }^{5,6}$

In a study it is said that early explantation is necessary for wound healing ${ }^{3}$ however, we had to explant one implant for wound healing after reinfection with biofilm. Infection with pseudomonas and late presentation could be the reason for explantation.

After extensive search of literature, we found Polyhexanide and Betaine are safe to use for the management of biofilm infection in implants made of titanium alloy. This suggested that it is safe to use in biofilms in cochlear implants. 7,10

\section{Conclusion}

The following factors can positively influence the reduced incidence of biofilm formation.

1. Strict asepsis,

2. Respecting the flap

3. Avoid using tie over (a better alternative is a snugly fitting periosteal pocket), treating hematomas at the earliest, giving adequate attention and proper treatment to otitis media with or without discharge.

Counselling regarding infection needs to happen as parents tend to take local treatment first which unknowingly leads to a delay before turning up at the cochlear implant centre. Polyhexanide and betaine surfactants 
are easily available and can be used against biofilms. However, we need more studies on biofilm management to make proper guidelines.

Conflicts of Interest: The authors have no conflicts of interest to declare.

Funds: This research did not receive any specific grant from any funding agencies in the public, commercial, or not for profit sectors

\section{Acknowledgements: None}

Data availability : data is available for review on request from the authors due to privacy/institutional ethical restrictions.

Ethical approval : The study was approved by the Institutional Ethics Committee

\section{REFERENCES}

1. Brady A, Loughlin R, Gilpin D, Kearney P, Tunney M. In vitro activity of tea-tree oil against clinical skin isolates of meticillin-resistant and-sensitive Staphylococcus aureus and coagulase-negative staphylococci growing planktonically and as biofilms. Journal of medical microbiology. 2006 Oct 1;55(10):1375-80.

2. Cunningham III CD, Slattery III WH, Luxford WM. Postoperative infection in cochlear implant patients. Otolaryngology — Head and Neck Surgery. 2004 Jul;131(1):109-14.

3. Cohen NL, Hoffman RA. Complications of cochlear implant surgery in adults and children. Annals of Otology, Rhinology \& Laryngology. 1991 Sep;100(9):708-11.

4. Brady AJ, Farnan TB, Toner JG, Gilpin DF, Tunney MM. Treatment of a cochlear implant biofilm infection: a potential role for alternative antimicrobial agents. The Journal of Laryngology and Otology. 2010 Jul 1;124(7):729.

5. Flemming HC, Neu TR, Wozniak DJ. The EPS matrix: the "house of biofilm cells". Journal of bacteriology. 2007 Nov 15;189(22):7945-7.

6. Post JC, Stoodley P, Hall-Stoodley L, Ehrlich GD. The role of biofilms in otolaryngologic infections. Current opinion in otolaryngology \& head and neck surgery. 2004 Jun 1;12(3):185-90.

7. Hornschuh M, Zwicker P, Schmidt T, Finke B, Kramer A, Müller G. Poly (hexamethylene biguanide), adsorbed onto Ti-Al-V alloys, kills slime-producing Staphylococci and Pseudomonas aeruginosa without inhibiting SaOs-2 cell differentiation. Journal of Biomedical Materials Research Part B: Applied Biomaterials. $2020 \mathrm{Jul} ; 108(5): 1801-13$.

8. Germiller JA, El-Kashlan HK, Shah UK. Chronic Pseudomonas infections of cochlear implants. Otology \& neurotology. 2005 Mar 1;26(2):196-201.

9. Ruellan K, Frijns JH, Bloemberg GV, Hautefort C, Van den Abbeele T, Lamers GE, Herman P, Huy PT, Kania RE. Detection of bacterial biofilm on cochlear implants removed because of device failure, without evidence of infection. Otology \& Neurotology. 2010 Oct 1;31(8):1320-4.

10. Andriessen AE, Eberlein T. Assessment of a wound cleansing solution in the treatment of problem wounds. Wounds: a compendium of clinical research and practice. 2008 Jun 1;20(6):171-5.

\section{Hosted file}

figure 1.docx available at https://authorea.com/users/346038/articles/472122-title-salvagingcochlear-implant-after-suspected-biofilm-infection-our-experience

\section{Hosted file}


Figure 2.docx available at https://authorea.com/users/346038/articles/472122-title-salvagingcochlear-implant-after-suspected-biofilm-infection-our-experience

\section{Hosted file}

Figure 3.docx available at https://authorea.com/users/346038/articles/472122-title-salvagingcochlear-implant-after-suspected-biofilm-infection-our-experience

\section{Hosted file}

figure 4.docx available at https://authorea.com/users/346038/articles/472122-title-salvagingcochlear-implant-after-suspected-biofilm-infection-our-experience

\section{Hosted file}

Table.docx available at https://authorea.com/users/346038/articles/472122-title-salvagingcochlear-implant-after-suspected-biofilm-infection-our-experience 